Supporting information for

\title{
Synthesis of a Novel Poly(iptycene) Ladder Polymer
}

Zhihua Chen, John P. Amara, Timothy M. Swager*

Department of Chemistry, Massachusetts Institute of Technology, Cambridge, Massachusetts 02139

tswager@mit.edu

Experiments of ${ }^{13} \mathrm{C}$ distortionless enhancement by polarization transfer (DEPT) and ${ }^{1} \mathrm{H}-{ }^{13} \mathrm{C}$ heteronuclear multiple-bond correlation (HMBC) on compound $\mathbf{1 1}$ were carried out on a Varian Inova-500 MHz instruments.

CH3 carbons

CH2 carbons

$\mathrm{CH}$ carbons

all protonated carbons

145

140

135

130

125

120

ppm

Figure S1. ${ }^{13} \mathrm{C}$ DEPT NMR spectra of Compound 11 


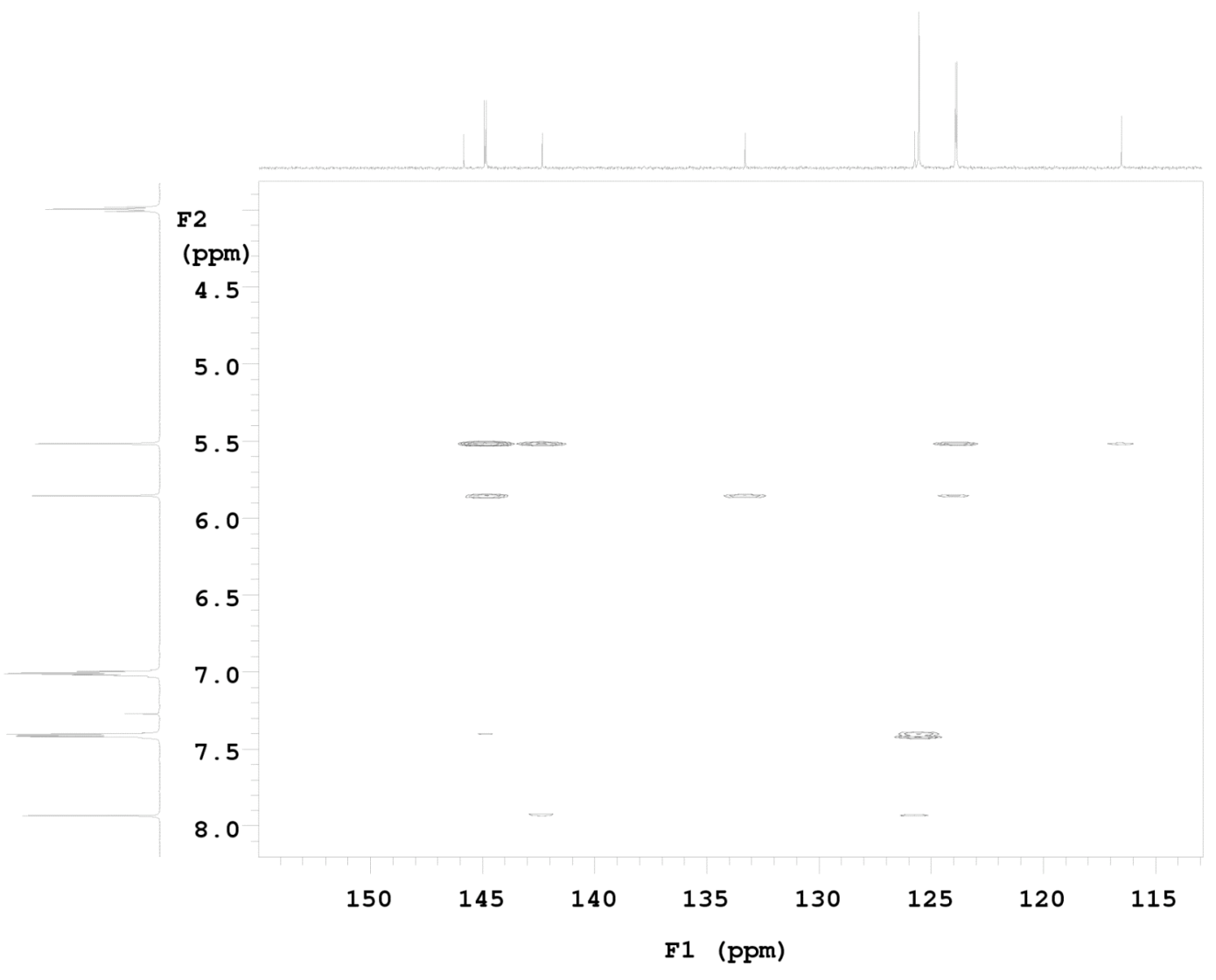

Figure S2. ${ }^{1} \mathrm{H}^{13} \mathrm{C}$ HMBC NMR spectrum of compound 11. 